\title{
Fracture in Complex Microstructures
}

\author{
Toshiro Kobayashi and Hiroyuki Toda \\ Department of Production Systems Engineering, Toyohashi University of Technology, Toyohashi 441-8580, Japan
}

\begin{abstract}
This paper reviews fracture features of a variety of conventional and advanced materials which consist of more than two different phases in terms of composite material. To be concrete, the materials include ductile cast irons, carburized steels, aluminum alloys, and several kinds of discontinuously-reinforced composites, all of which have been studied by the present authors to date. Firstly, features on fracture of the above-mentioned three conventional materials are introduced. Those have constructions common to artificial composites; particle reinforced composite and layered composites. In the latter half of this paper, the detailed mechanisms of deformation and fracture in artificial composites and those analyses mainly on the basis of continuum mechanics and fracture mechanics are shown. Deformation and fracture behaviors of "natural" (or in-situ) and artificial composites are discussed in terms of their similarities and discrepancies both from metallurgical and mechanical points of view in order to bring systematic understanding of the materials having complex microstructures. In addition, it is shown that certain phenomena that already constitute common knowledge in the field of composite materials, should be strongly considered in the field of conventional materials.
\end{abstract}

(Received July 17, 2000; Accepted August 21, 2000)

Keywords: composite, ductile cast iron, carburized steel, aluminum-lithium alloy, fracture, deformation, finite element analysis, fracture mechanics

\section{Introduction}

Currently, most advanced materials have complex microstructures. Therefore, the observation and analysis of the deformation and fracture behavior of composite materials should be extended to even such materials. In addition to advanced materials, many conventional metallic materials such as cast iron and cast aluminum are naturally composite and should also be investigated from such a viewpoint. Ductile cast iron is a steel-base composite material in which spherical graphite particles are dispersed. Aluminum-silicon casting alloy can be considered to be an aluminum-matrix composite material in which hard silicon particles are dispersed, although the particle size is of the order of several to several tens of micrometers. Iron and steel materials are widely known to contain pearlitic structures with cementite and ferrite layers. Recent refining methods such as heavy plastic deformation are capable of producing ultra high-strength materials that are similar to multi-layered composites.

The exact and systematic understanding of the deformation and fracture behavior of advanced and conventional complex microstructures is important. This paper is based on previous studies by the authors into the properties and behavior of various advanced and conventional materials. This paper will summarize the experimental observations and mechanical analysis of micromechanics and continuum mechanics that have been conducted in order to clarify microscopic damage behavior, deformation and fracture behavior, and fatigue crack initiation and growth behavior. The characteristics of these behaviors are clarified and compared in order to provide valuable reference data for discussion of the deformation and fracture behavior of various materials.

\section{Fracture Mechanism of Ductile Cast Iron}

Cast iron is prevalent in society due to economic factors. To great interest, ductile cast iron, such as austempered ductile cast iron (ADI) is becoming popular because of its high tensile strength of more than $1000 \mathrm{MPa}$, and elongation of $10 \%$ or more. ${ }^{1)}$ The microstructure of ductile cast iron is complicated due to eutectic cell solidification, during which $\gamma$ phase surrounds nodule of graphite (strength is as low as $10 \mathrm{MPa}$ ). The matrix can vary from $100 \%$ ferrite to $100 \%$ pearlite as a function of cooling speed and other factors. Figure 1 shows the fracture mechanism for the $100 \%$ ferrite case. A ductile crack initiates at the graphite interface and grows into a large void that coalesces with other voids. ${ }^{1)}$ During this process, inclusions may also form small voids and promote the coalescence of large voids. In the brittle low-temperature region, cleavage fractures are thought to occur at carbide or inclusion at eutectic cell boundaries. Carbide forms easily during eutectic solidification as a result of the segregation of manganese and other elements. This indicates that the fracture initiation point can change if plastic constraints suppress slip deformation. Figure 2 shows changes in the elastic-plastic fracture toughness, $J_{\text {IC }}$, for increasing brittle pearlite. ${ }^{2)}$

In cast iron, a ferrite layer surrounds graphite nodules and pearlite occupies the remaining areas in a form called a bull'seye structure. Figure 3 shows the results of deformation

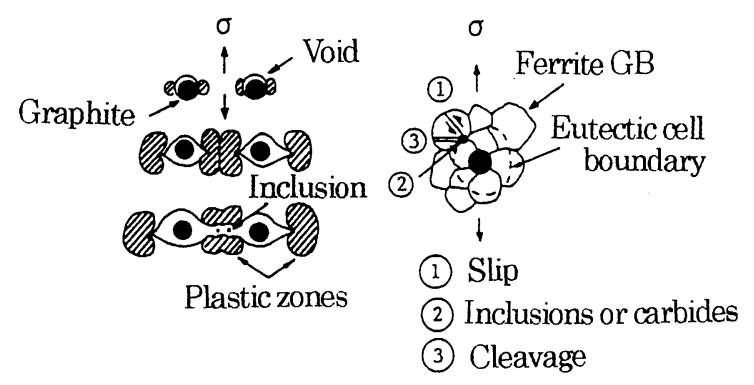

(a) Ductile crack

Fig. 1 Crack initiation and propagation mechanisms in ferrite matrix ductile case irons. 


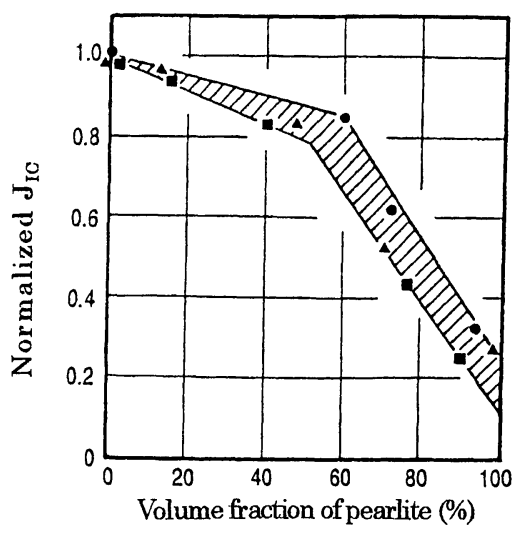

Fig. $2 J_{\text {IC }}$ as a function of volume fraction of pearlite at $293 \mathrm{~K} . J_{\text {IC }}$ is normalized by that for $100 \%$ ferrite matrix.

mechanism analysis of such ductile cast iron. The equivalent stresses at $0.2 \%$ strain were analyzed for a quarter model of a period-symmetric cell where the graphite particles were assumed to be voids. ${ }^{3)}$ When the ferrite ring is thin, fractures occur at the ferrite/pearlite interface perpendicular to the tensile direction. If the ferrite phase is more pronounced, however, the concentration of stress shifts into the pearlite (i.e., eutectic cell boundary). This was confirmed by in-situ SEM observations of material testing. The stress concentration is reduced in the ferrite region, but this increases the stress level in the pearlite region. Hence, the fracture position shifts when ferrite is increased. According to this analysis, the volume fraction of ferrite that exhibits the least stress concentration is approximately $15 \%{ }^{3)}$ This appears to be an important guideline for the microstructural design of this material. Further studies are required for a detailed analysis.

\section{Fracture of Carburized Steels}

A carburized layer is usually formed as a hard layer less than $1 \mathrm{~mm}$ on the surface of steel, and is known to endow the steel with improved wear resistance, fatigue strength, and other characteristics. The fracture of this kind of material is controlled by the brittle surface, and not by the soft inter-

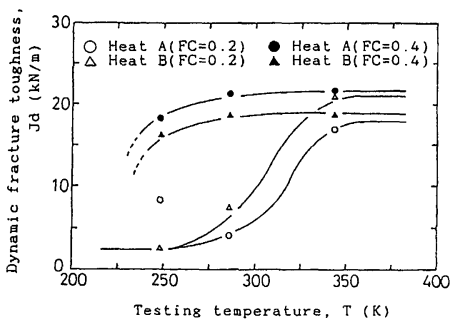

Fig. 4 Dynamic fracture toughness as a function of temperature in carburized steels having different crack lengths.

nal structure. For this study, the authors produced specimens by carburizing a sample, even to the notch-tip, and then precracking from the notch-tip with cracks 0.2 and $0.4 \mathrm{~mm}$ long. Figure 4 shows the dynamic fracture toughness of the specimens ${ }^{4)}$ as a function of temperature. Surprisingly, the short pre-crack of $0.2 \mathrm{~mm}$ exhibited a remarkable increase in brittle/ductile transition temperature. This is because the tip of the pre-crack is within the hard brittle layer that has a higher carbon content. It should be noted that if a crack occurs in this kind of carburized layer, the material is less likely to fracture if the tip of the crack reaches the soft subsurface material. Residual compressive stress is considered to contribute significantly to the improvement of fatigue strength after carburizing.

Figure 5 shows an example in which the stress is greatest at about $60 \mu \mathrm{m}$ from the material surface. ${ }^{5)}$ Here $\mathrm{E}$ is effective case depth. Conventional fatigue tests and impact fatigue tests, in which an impact force is applied cyclically, were conducted on the specimens. As Fig. 6 shows, deterioration in impact fatigue is remarkable in the high cycle region. It can also be seen that deeper effective case depth yields higher fatigue strength. Each of the curves has an inflection point below which a fish-eye fracture initiated from the interior, while it is initiated at the surface in the region above the inflection point.

Figure 7 shows an example of a shot peened specimen. Shot peening is conducted in order to reduce residual austenite in the carburized layer and to increase residual compressive stress. ${ }^{6)}$ Shot peening was found to improve impact fa-

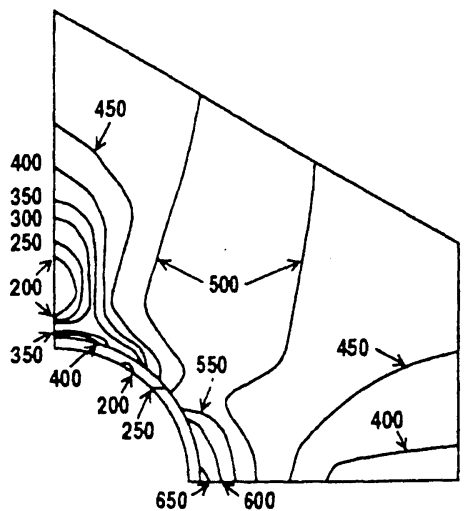

(a) Pearlite:98\%

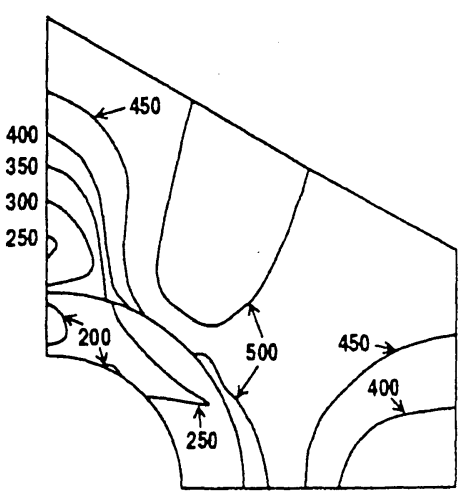

(b) Pearlite:87.2\%

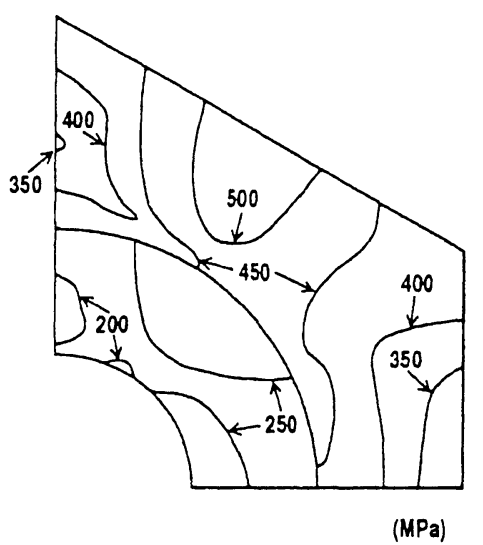

(c) Pearlite:70\%

Fig. 3 Contour maps of equivalent stress predicted by finite element analysis, representing effects of pearlite fraction in a Bull's eye ductile cast iron. 
tigue strength to a constant level, irrespective of steel type. ${ }^{7)}$ In particular, improvement of fatigue strength in the high cycle region is remarkable due to increases in surface hardness and compressive residual stress.

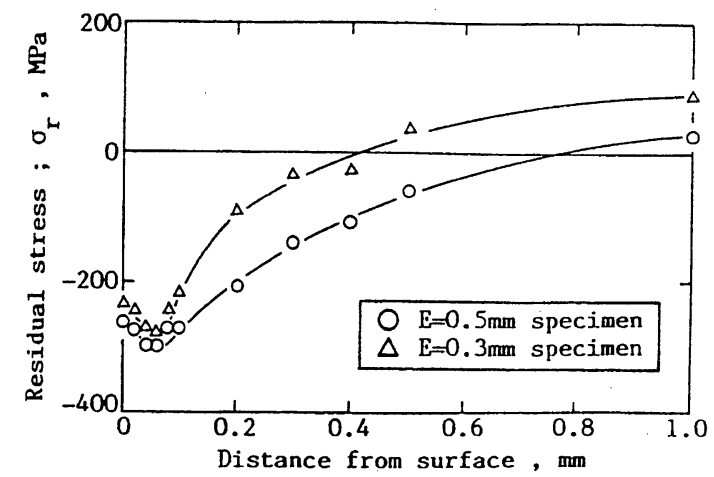

Fig. 5 Residual stress distributions beneath surface in carburized SCM415 steel with two levels of the case depth.
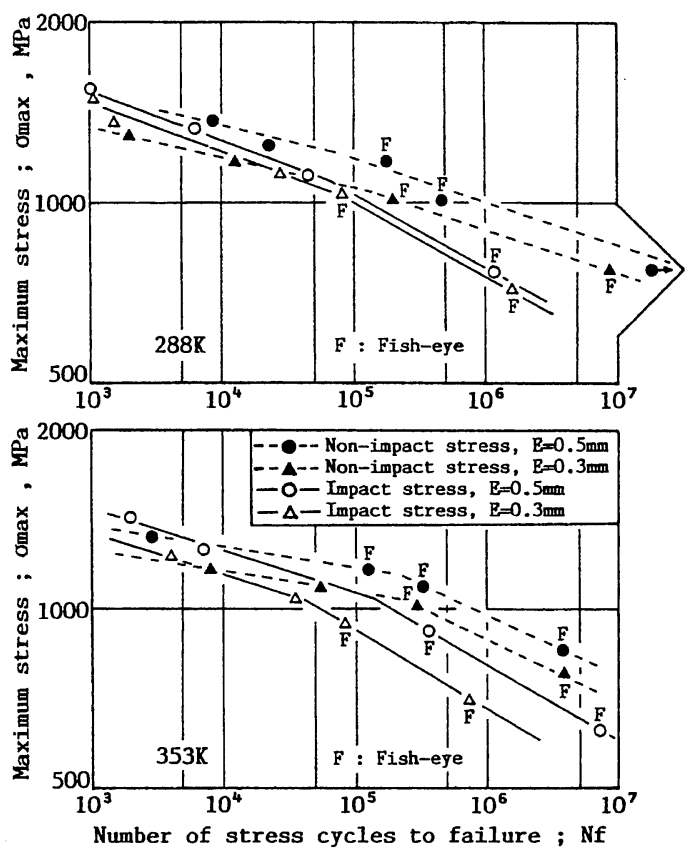

Fig. $6 \mathrm{~S}-\mathrm{N}$ curves in ordinary and impact fatigue tests of the carburized SCM415 steels.

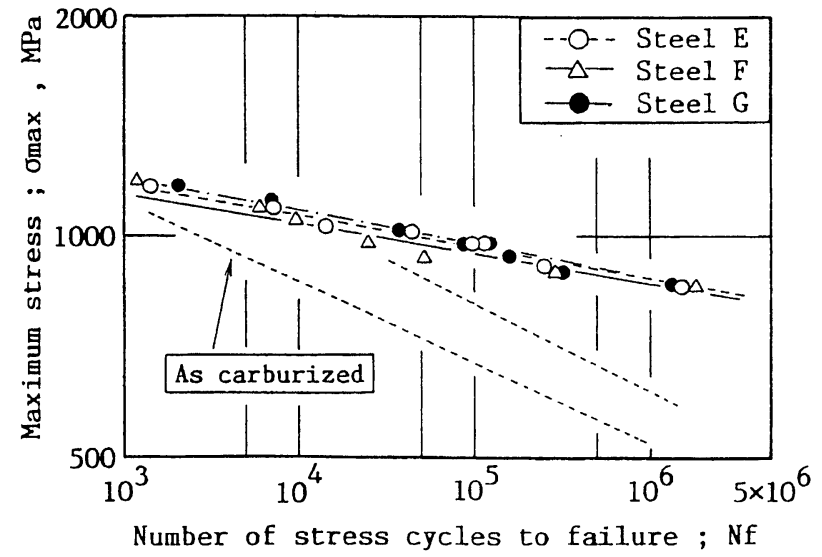

Fig. 7 Effects of shot peening (solid lines) on impact fatigue properties of carburized steels.

\section{Formation of Delamination Cracking in Al-Li Alloy}

Lithium (Li) is the lightest of the metallic elements with a specific gravity of 0.53 . Adding 1 mass $\%$ lithium to aluminum reduces the overall weight by $3 \%$ and increases the shear modulus by $6 \%$. Using conventional I/M methods, the reactivity of lithium limits the maximum lithium content of an alloy to $3 \%$ or less. Generally, $\mathrm{Al}-\mathrm{Li}-\mathrm{Cu}-(\mathrm{Mg})-\mathrm{Zr}$ alloy is used, in which the intermetallic phase $\delta^{\prime}\left(\mathrm{Al}_{3} \mathrm{Li}\right)$ that is coherent with the matrix contributes to strengthening. This intermetallic phase is easily cut by dislocation motion, and promotes the accumulation of dislocations at grain boundaries, thus inducing grain boundary cracking. ${ }^{7)}$ However, this alloy is peculiar in that its toughness increases with decreasing temperature, as shown in Fig. 8. Because of this peculiar behavior, the alloy is used as the fuel tanks of space shuttles.

At low temperatures at which toughness is high, rolling deformation causes delamination cracking (intergranular cracking) because of the fibrous texture. Figure 9 shows the relationship between orientations of the fibrous microstructure and crack growth direction. ${ }^{8)}$ Toughness is known to generally increase if cracking is divided or arrested. The growth of a crack is generally anticipated to be most likely in the case of crack divider. However, delamination cracking in the case of crack divider orientation actually improves fracture toughness due to changes in the stress condition from plane strain

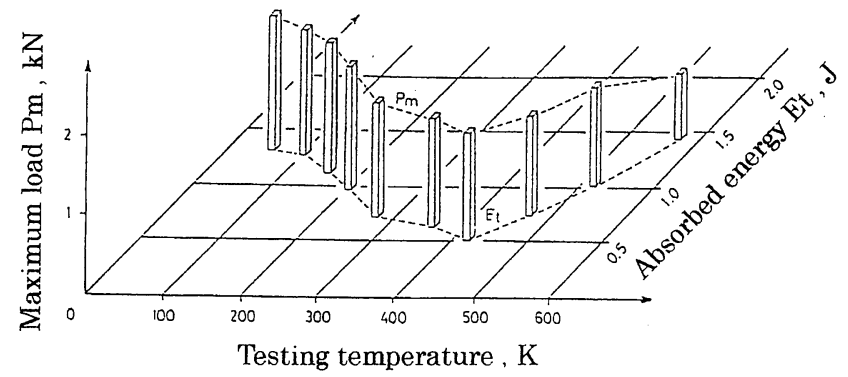

Fig. 8 Variations of maximum load, $P m$, and total absorded energy, $E t$, with temperature in the instrumented impact tests of an $\mathrm{Al}-\mathrm{Li}-\mathrm{Cu}-\mathrm{Mg}-\mathrm{Zr} / \mathrm{T} 6$ alloy.
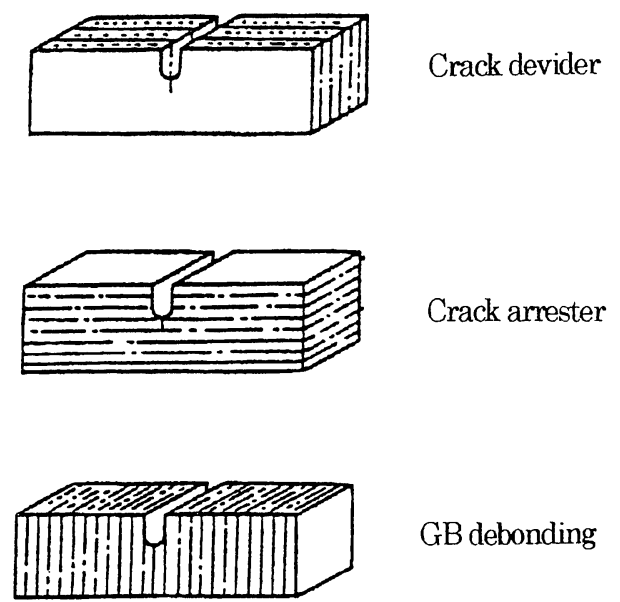

GB debonding

Fig. 9 Various fracture morphologies through fibrous textures in rolled aluminum alloys. 
to plane stress, and also due to stress relaxation at a crack tip. ${ }^{9)}$ This may be cause of the high toughness of the alloy at low temperatures. Such toughening may be based on extrinsic factors. An analysis of the stress levels that cause delamination was conducted. Figure 10 shows the onset of delamination at liquid helium temperature and at room temperature as determined from ultrasonic velocity measurements of the specimens for which testing was interrupted for measurement at each stress stage. ${ }^{10)}$ The stresses were about $335 \mathrm{MPa}$ at liquid helium temperature and $357 \mathrm{MPa}$ at room temperature. However, the same stresses change to 116 and $113 \mathrm{MPa}$, respectively, if converted into stresses that are perpendicular to the grain boundaries. These observations clarified that extremely low stress can cause debonding ahead of a crack.

Al-Li alloy contains many coarse inclusions which are formed during casting, that are known to significantly affect fracture behavior. However, there have been no reports on the quantitative analysis of these inclusions to date. In-situ SEM observations, analysis of HRR stress fields and Eshellby equivalent inclusion models have recently been used for obtaining the fracture strength of inclusion particles in $\mathrm{Al}-\mathrm{Li}$ alloy. ${ }^{11)}$ Figure 11 shows the distribution of inclusions $\left(\mathrm{CuAl}_{2}\right.$ and $\mathrm{Al}_{2} \mathrm{CuMg}$ ) by size. According to this figure, inclusions over $6 \mu \mathrm{m}$ are more likely to fracture than smaller inclusions. Figure 12 shows the calculated particle fracture strengths. The distribution of inclusion fracture strength within each inclusion size range was approximated using the Weibull distribution with two parameters. The expected value is shown as a solid circle. At inclusion sizes of 5 to $8 \mu \mathrm{m}$, the fracture strengths of the two kinds of inclusions are almost equal: $710 \mathrm{MPa}$ for $\mathrm{CuAl}_{2}$ and $715 \mathrm{MPa}$ for $\mathrm{Al}_{2} \mathrm{CuMg}$. At inclu-
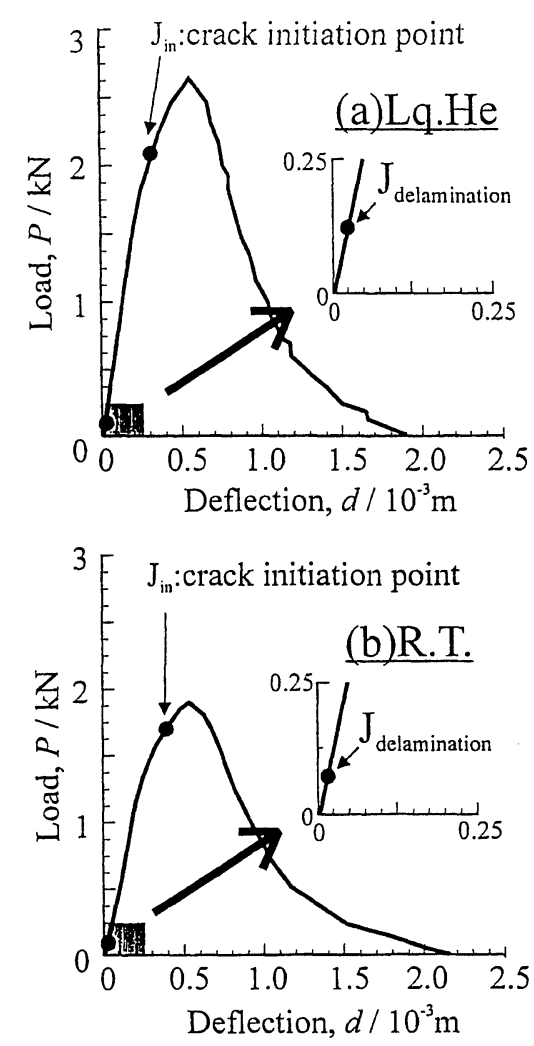

Fig. 10 Load-deflection curves at (a) liquid helium and (b) room temperatures in the fracture toughness test of A2091 Al-Li alloy, illustrating the predicted onset of delamination at respective temperature.
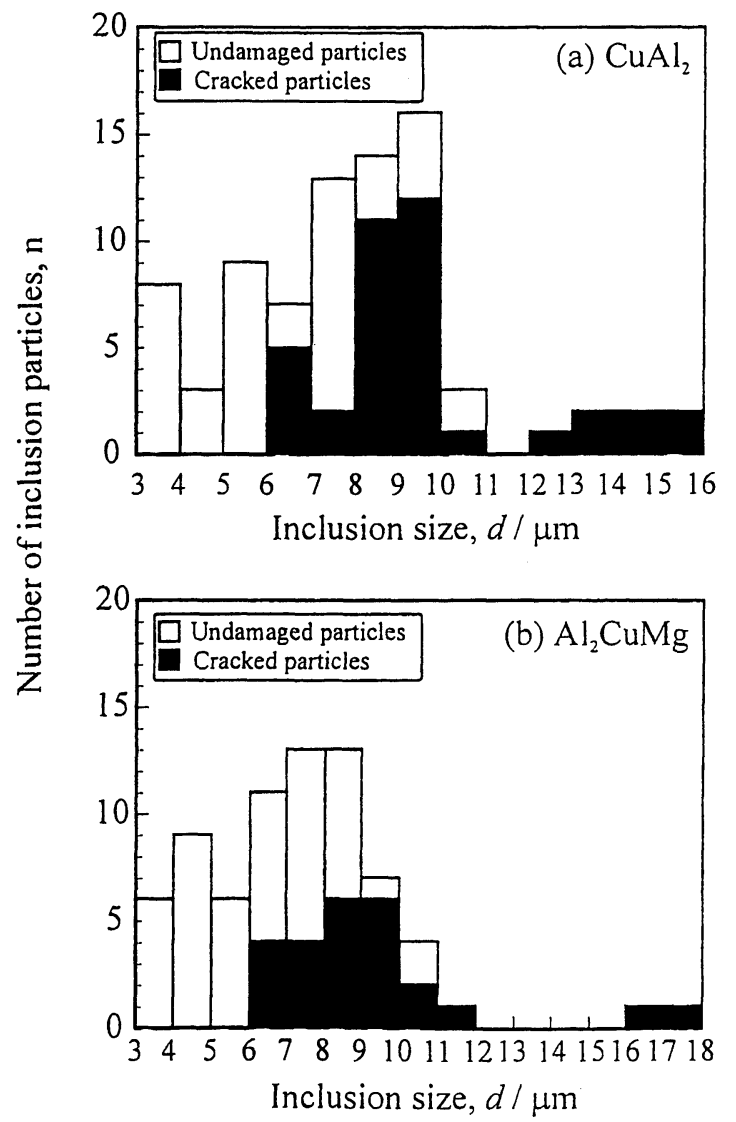

Fig. 11 Histograms of number of inclusion particles in some A2091 Al-Li alloy.

sion sizes of 14 to $18 \mu \mathrm{m}$, however, the fracture strength of $\mathrm{Al}_{2} \mathrm{CuMg}$ is $540 \mathrm{MPa}$, which is not overly different from the tensile strength of this alloy itself. Although not shown here, fractures were not observed in $\mathrm{Al}_{3} \mathrm{Zr}$ and $\mathrm{Al}_{3} \mathrm{Ti}$ particles, even in particle diameters over $10 \mu \mathrm{m}$. The fracture strength may be at least $1000 \mathrm{MPa}$ also, when predicted from the lower limit. Since the fracture strengths of inclusions differ remarkably, and are dependent on the particle properties, controlling these properties is extremely important in the material manufacturing processes.

\section{Fracture of Composite Material}

\subsection{Microcrack and crack growth}

The authors have primarily studied the $\mathrm{Al}-\mathrm{SiC}_{\mathrm{w}}$ system in metal matrix composites (MMC) and also examined particle reinforced MMCs. It was experimentally verified that fractures of reinforcement or interfacial debonding causes damage (i.e. microcrack initiation) dynamically ahead of the main crack, irrespective of reinforcement. Figure 13 shows an example of the elastic-plastic analysis of the stresses and strain distribution in the matrix by the finite element method for a tensile load applied parallel to reinforcement. ${ }^{12)}$ The effective stress, $\sigma_{\text {eff }}$, is concentrated at the whisker edge (Fig. 13(a)) and plastic strain occurs (Fig. 13(c)). An initial void is often formed at this position. At the same time, the plastic constraint increases stress triaxiality and hydrostatic stress develops in the matrix (Fig. 13(b)). Thus, a large axial stress can be accommodated without significant plastic deformation. This 


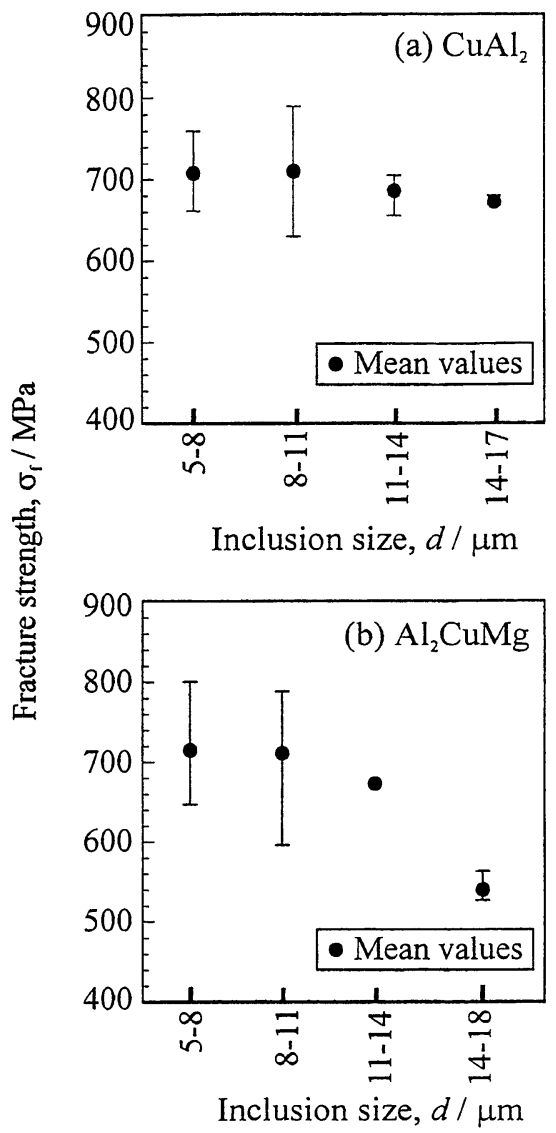

Fig. 12 Changes of fracture strengths of inclusions with size of (a) $\mathrm{CuAl}_{2}$ and (b) $\mathrm{Al}_{2} \mathrm{CuMg}$ in some A2091 Al-Li alloy.

is the most significant characteristic of complex microstructures. ${ }^{12)}$ Figure 14 shows the distribution of the stress component, $\sigma_{\mathrm{z}}$, in the direction of axial stress in the reinforcement. The stress component is as high as $2.5 \mathrm{GPa}$ or more under a tensile load of $400 \mathrm{MPa}$ around the center of the reinforcement. The size, shape, and distribution of the reinforcement determines the occurrence of fractures or interfacial debonding. Figure 15 shows an example of the analysis of local shear stress, $\tau_{\mathrm{rz}}$, and normal stress, $\sigma_{\mathrm{r}}$, at an interface. $\tau_{\text {rz }}$ here is $150 \mathrm{MPa}$, which is markedly smaller than the $1690 \mathrm{MPa}$ reported in the literature. ${ }^{13)}$ This indicates that interfacial debonding is difficult to induce.

The authors have previously created a simulation program in order to study the effect of microcracks initiating in reinforcement on the growth of the main crack. ${ }^{14)}$ Figure 16 shows five separate cases where the initial distance between the main crack surface and a microcrack ahead of it ranges from 0 to $8 \mu \mathrm{m}$ in the vertical direction. When the distance between the main crack and the microcrack is within a few micrometers, the growth path of the main crack is significantly affected. From similar analysis, the microcrack induces the anti-shielding effect when the microcrack is located ahead of the main crack, and induces the shielding effect when the microcrack is located behind the main crack. ${ }^{14)}$ Crack propagation toughness is known to improve if the crack growth direction is deflected. Toughening may be attributable to these extrinsic factors. This is further detailed in 5.3.

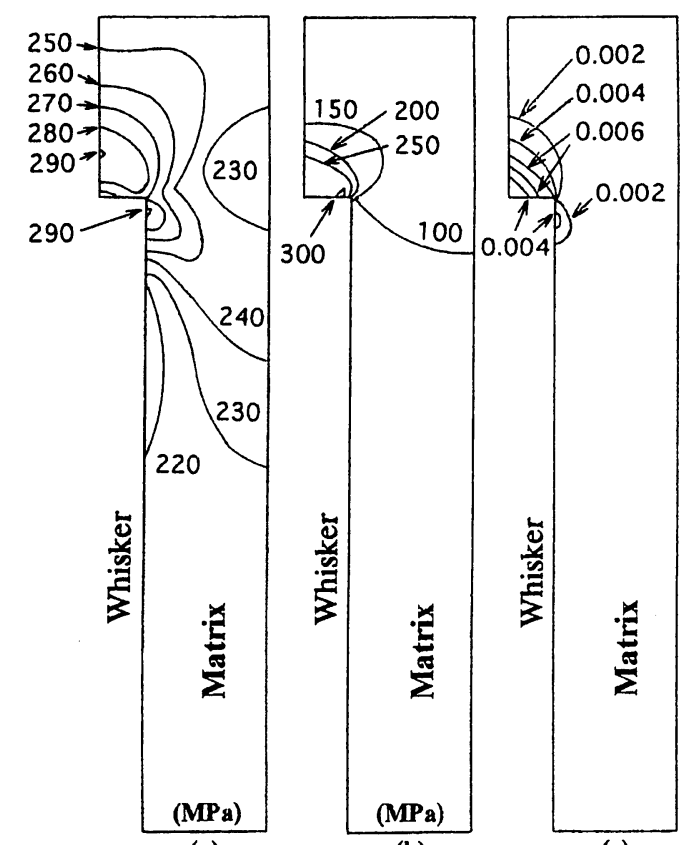

(a)

(b)

(c)

Fig. 13 Finite element predictions of (a) effective stress, (b) hydrostatic stress and (c) effective plastic strain in one-fourths models of $\mathrm{SiC}_{\mathrm{w}} / 6061$ Al composites. Applied stress is $300 \mathrm{MPa}$.

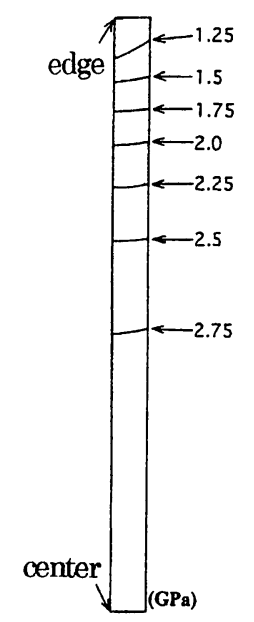

Fig. 14 Finite element predictions of axial stress in an one-fourths model of $\mathrm{SiC}_{\mathrm{w}} / 6061 \mathrm{Al}$ composites. Applied stress is $400 \mathrm{MPa}$.

\subsection{Influence of the PFZ layer around the reinforcement}

In age-hardenable aluminum alloys, a precipitate-free zone (PFZ) is formed near grain boundaries. This is a well-known fact, and is generally considered undesirable because heterogeneous deformation can occur in PFZ. The main aluminum alloy handled by the authors is 6061 alloy (Al-Mg-Si system), which is well known to be hardened by aging. This alloy forms PFZ near the reinforcement. ${ }^{15)}$ Figure 17 shows the stress-strain curve predicted by FEM analysis. The strength is rather low due to the existence of PFZ. If this kind of PFZ appears, coarse precipitates generally form at the interface. The authors have generated various models, as shown in Fig. 18: ${ }^{16)}$

(b) Peak-aged (PA) model: The PFZ width is $44 \mathrm{~nm}$ and precipitates of $22 \mathrm{~nm} \times 22 \mathrm{~nm}$ (coverage: $9.7 \%$ ) exist on the in- 


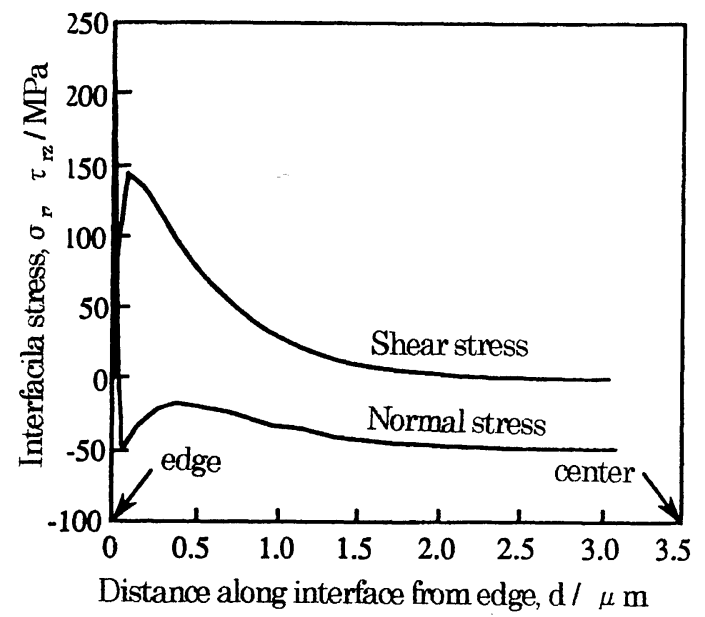

Fig. 15 The same prediction with Fig. 13. Variations of interfacial shear and normal stresses.

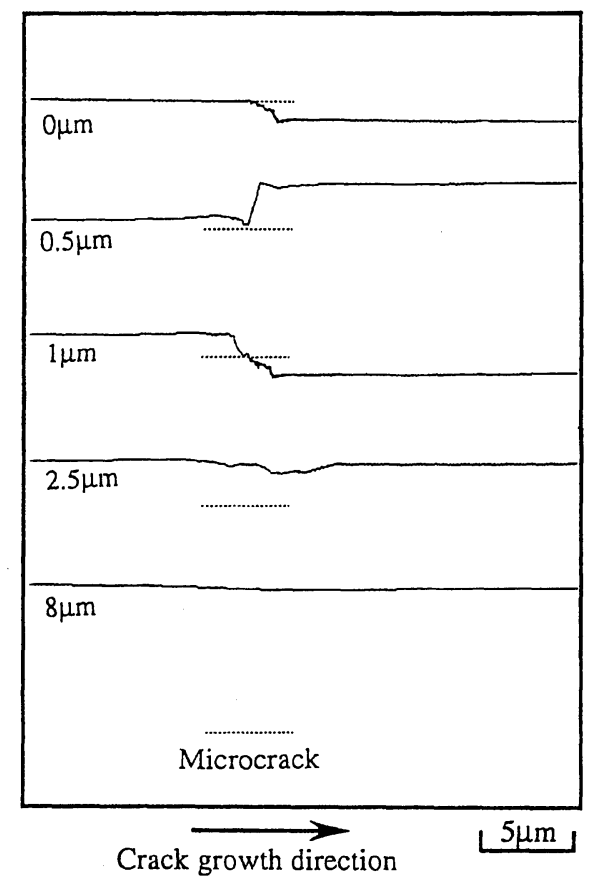

Fig. 16 Numerical simulation on basis of the fracture mechanics, representing the effects of a pre-existing microcrack on crack paths in a $\mathrm{SiC}_{\mathrm{w}} / 6061 \mathrm{Al}$ composite.

terface.

(c) Over-aged (OA) model: The PFZ width is $90 \mathrm{~nm}$ and precipitates of $44 \mathrm{~nm} \times 44 \mathrm{~nm}$ (coverage: $66 \%$ ) exist on the interface.

The stress-strain curves show the same tendency as those in Fig. 17. Overall, precipitates were not observed to have any great influence on the stress-strain relationship. Figure 18 shows the distribution of effective plastic strains. The large strain zone extended remarkably with increasing PFZ. The maximum value occurred at the edge of a whisker (Fig. 18(a)) with no precipitates, but occurred at the edge of the top precipitate when there were precipitates. Hydrostatic pressure showed a marked rise at the edge of the whisker in Figs. 18(b) and (c). ${ }^{16)}$ Precipitates appear to obstruct the preferential plastic flow in the PFZ and suppress any decrease in strength. The

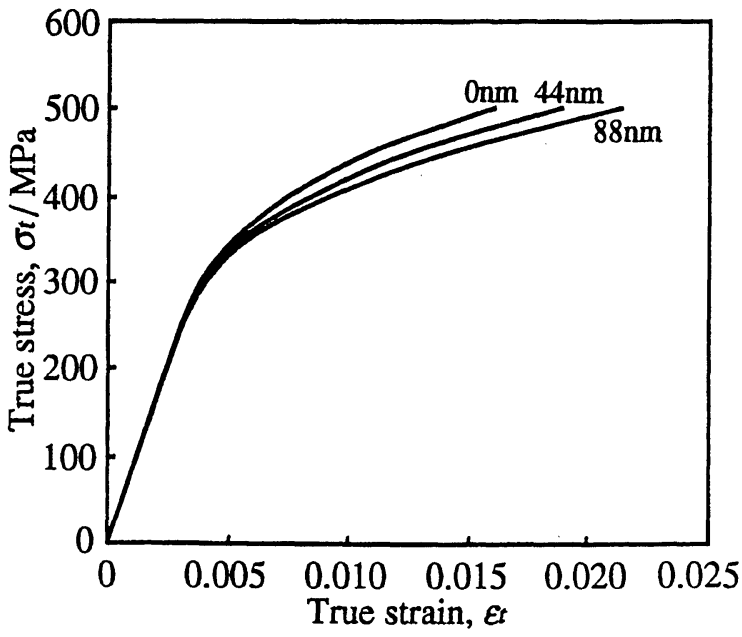

Fig. 17 Finite element prediction of the effect of the PFZ layer thickness on the stress-strain curve of $6061 \mathrm{Al}-22 \mathrm{vol} \% \mathrm{SiC}$ composites.

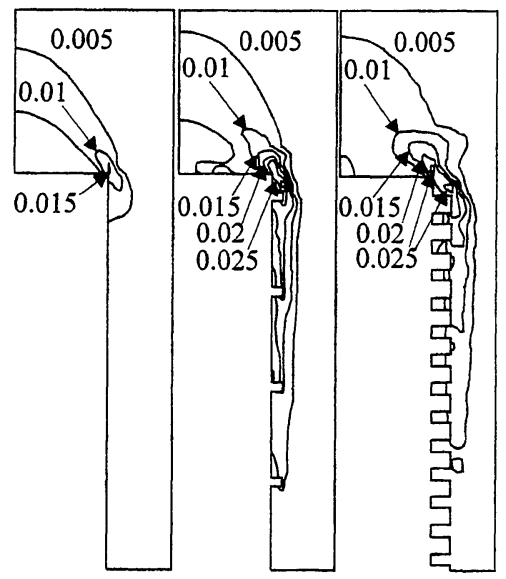

(a)

(b)

(c)

Fig. 18 The same prediction with Fig. 13, representing the effects of PFZ layers and coarse precipitates at interface on effective plastic strain.

strength of the precipitates is based on a Young's modulus of $120 \mathrm{GPa}$ and a Poisson's ratio of 0.27 for the $\mathrm{Mg}_{2} \mathrm{Si}$ equilibrium phase, ignoring the morphology of the precipitates, which makes the interface brittle and weak. When the intermetallic phase with elastic modulus in the intermediate level between the whisker and matrix exists, the stress-strain curves tend to exhibit higher strengths than if there were no PFZ. ${ }^{16)}$ This may be an important point in some applications.

Non-equilibrium segregation of the solute atoms in 6061 $\mathrm{Al}-\mathrm{SiC}_{\mathrm{w}}$ occurred at the interface with a remarkably high Mg concentration. ${ }^{17)}$ Figure 19 shows the $\mathrm{Al}-\mathrm{Mg}_{2} \mathrm{Si}$ pseudobinary phase diagram. From the figure, it can be seen that temporarily heating sample with average solute concentration $C_{\mathrm{A}}$ to temperature $T_{\mathrm{A}}$ causes aging to accelerate in the vicinity of the interface where $\mathrm{Mg}$ concentration is high, and GP zone resolution where $\mathrm{Mg}$ concentration is low. Consequently, the PFZ shrinks and the composite materials become homogeneous. The authors have reported that such heat-treatment is one of the applications of retrogression \& reaging treatment (RRA), which can improve the strength of composite materials by about $10 \% .^{17)}$ 


\subsection{Toughening by the introduction of agglomerated re-} inforcement

When creating the simulation program mentioned in 5.1, the authors quantified the dispersion of the reinforcement ${ }^{14}$ ) using random numbers obtained from:

(1) Homogeneous distribution = binomial distribution

(2) Random distribution $=$ Poisson distribution

(3) Agglomerated distribution with clusters = Pólya-Eggenberger distribution

The results of the simulation of crack growth processes under random distribution and agglomerated distribution conditions ${ }^{18)}$ show that crack deflection plays a significant role in the crack propagation path in agglomerated composites. Figure 20 shows the variation of roughness in the predicted propagation path as a function of the distribution mode. What is obvious from this figure is that the growth path is deflected most and becomes rough in a somewhat agglomerated distribution. Toughness is a measure of resistance to crack initiation and growth. These findings suggest that the reinforcement should be agglomerated to some extent, especially in order to improve growth resistance.

The authors agglomerated SiC whiskers by the spray drying technique, and then dispersed the clusters into a $6061 \mathrm{Al}$ alloy matrix by high-pressure casting. ${ }^{18)}$ Figure 21 shows the microstructure and the load-displacement curves in a threepoint bending test. The agglomerated composite clearly shows a remarkable improvement in ductility prior to rupture. The main factors of this improvement are that microcracks occurs in the agglomerate first, followed by growth of the main crack through the matrix towards the microcracks, and that the crack growth path deflected. The results did not support the preconceived idea that reinforcement in composite material should be as homogeneous as possible. This poses an interesting problem. These results are discussed in detail in the next section.

\subsection{Model analysis regarding the manifestation of high strength}

As mentioned in 5.3, the dispersion of reinforcement in a

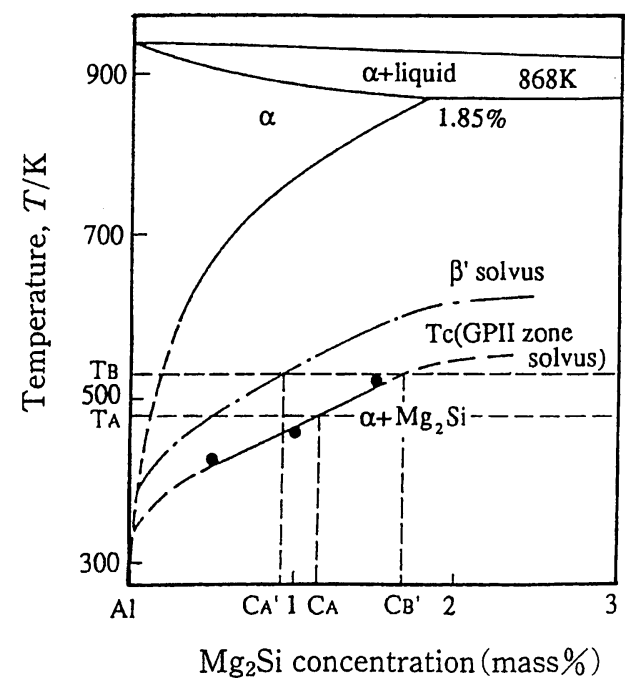

Fig. 19 Pseudo-binary phase diagram for $\mathrm{Al}-\mathrm{Mg}-\mathrm{Si}$, including $\beta^{\prime}$ and GP II zone solvus curves, representing the difference in solvus temperatures with distance from intreface. composite material strengthens the material more effectively if there is agglomeration. Opposing results have also been reported, however, to obtain effective strengthening without agglomeration requires that the material is free of fabrication de-

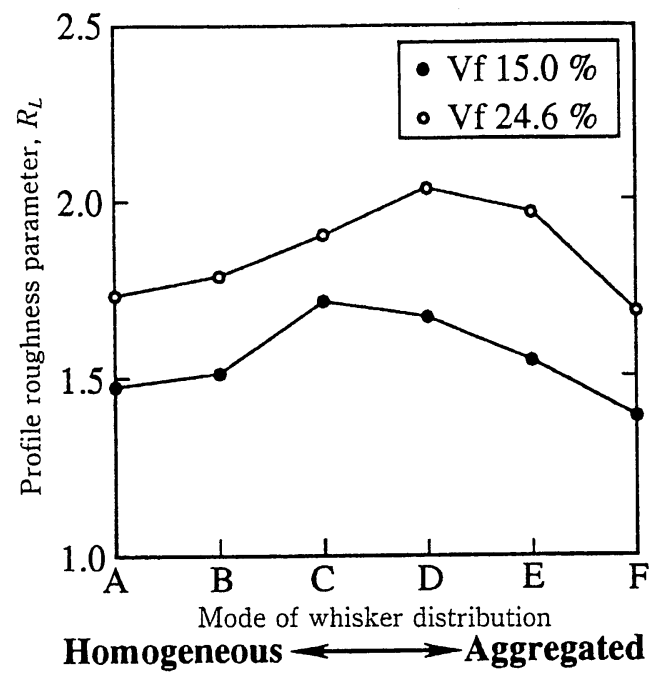

Fig. 20 Effects of spatial distribution patterns of $\mathrm{SiC}_{\mathrm{w}}$ on crack propagation resistance due to the same simulation with Fig. 16.
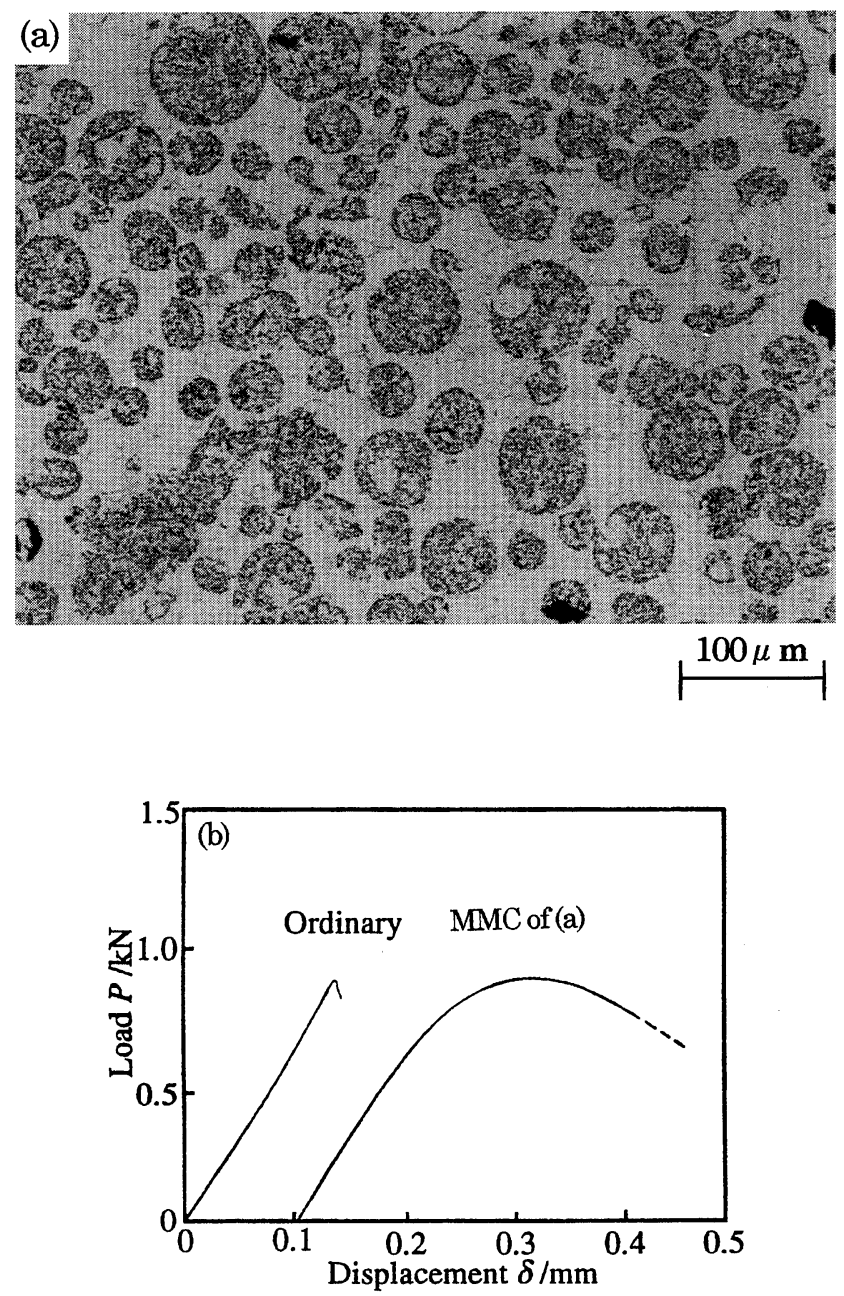

Fig. 21 Optical microstructure of a $\mathrm{SiC}_{\mathrm{w}} / 6061 \mathrm{Al}$ composite in which $\mathrm{SiC}_{\mathrm{w}}$ are artificially clustered. (b) is load-deflection curves in fracture toughness test. 
fects and that the reinforcement in the agglomerate is uniform. The authors studied the optimization for high strength by the FEM analysis of quarter models in terms of plane strain, periodic alignment of an unit cell, and axi-symmetric condition. ${ }^{19)}$ In Fig. 22, cubic phases of equal size and shape were isolated (a), in network form (b), and dispersed uniformly (c). For all of these models, the degree of clustering of the reinforcement is represented by the volume fraction, $V_{\mathrm{H}}$, in the agglomerated area and by $V_{\mathrm{L}}$ in the remaining matrix area. Each model was analyzed in terms of pure $\mathrm{Al}$ and $\mathrm{SiC}_{\mathrm{p}}$ for the overall fraction of reinforcement was $25 \%$ for the degree of agglomeration. The stress at total strain of $1 \%$ indicates that strengthening efficiency is higher in the network model and increases with the degree of agglomeration. This is probably because the preferential plastic deformation of the unreinforced matrix eases secondary internal stresses that are generated in the agglomeration phase by solitary agglomeration. Figure 23 shows the strengthening efficiencies of composite materials arranged in terms of the secant modulus ratio of the reinforced phase to the unreinforced phase for an average volume fraction of reinforcement in each composite material of $25 \%{ }^{19)}$ According to this figure, there is some degree of agglomeration at the highest strengthening efficiency. If pure aluminum is used, the optimum secant modulus ratio is between about 100 and 1000 , and about 100 for the 2124-T6 material. This kind of analysis has important implications in the design of composite materials. This analysis does not reflect how the volume fraction of reinforcement, $V_{\mathrm{H}}$, affects the entire material. The influences should be studied in future.

\subsection{Growth characteristic of short fatigue cracks}

Lastly, this paper describes the fatigue characteristics of composite materials, and crack propagation behavior in particular. As mentioned so far, low toughness is the biggest disadvantage of composite materials, but fatigue is also a critical problem. Composite materials generally show good fatigue characteristics. Figure 24 shows the crack growth characteristics of $6061 \mathrm{Al}$ alloy and the $22 \% \mathrm{SiC}_{\mathrm{w}}$ composite material. ${ }^{20}$ ) The threshold level, $\Delta K_{\mathrm{th}}$, is higher in composite materials. However, in composite materials, the growth rate starts rising in the latter half of stage IIb and then becomes unstable. ${ }^{20}$ ) Figure 25 shows this crack growth process schematically. In the plastic region near the tip of the main crack, fractures of the whisker, interfacial debonding, and expansion of the defects at contacts between whiskers or in uninfiltrated regions occur, and then grow and coalesce into secondary cracks. The main crack threads its way through the secondary cracks, thereby increasing the fracture surface roughness.

The growth characteristics of short fatigue cracks generally pose problems ${ }^{21)}$ when

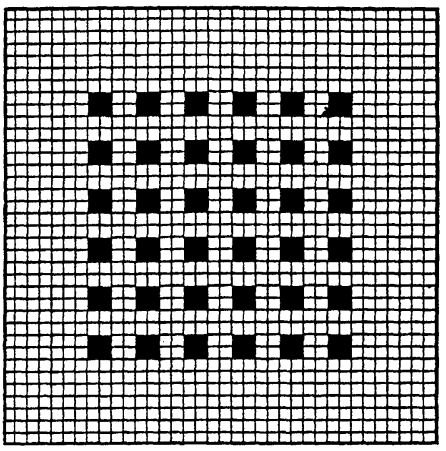

Isolated model $\left(V_{H}=25.0 \%\right)$

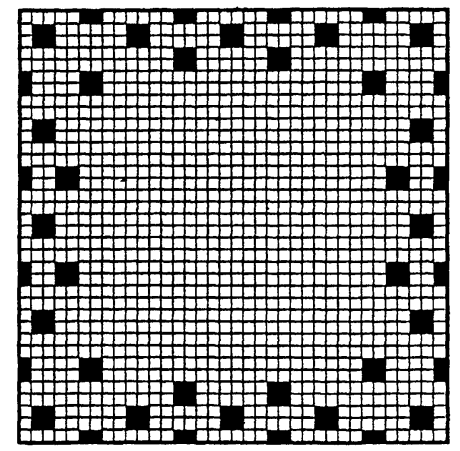

Network model $\left(V_{H}=25.0 \%\right)$

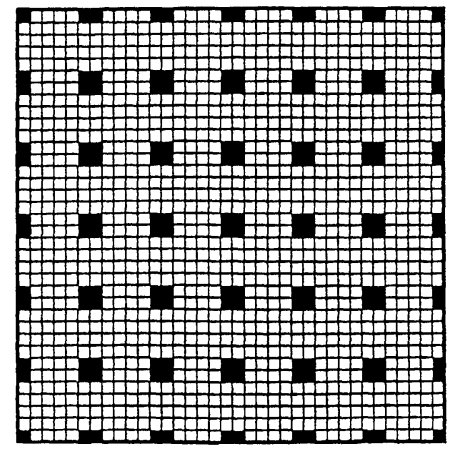

Uniform model

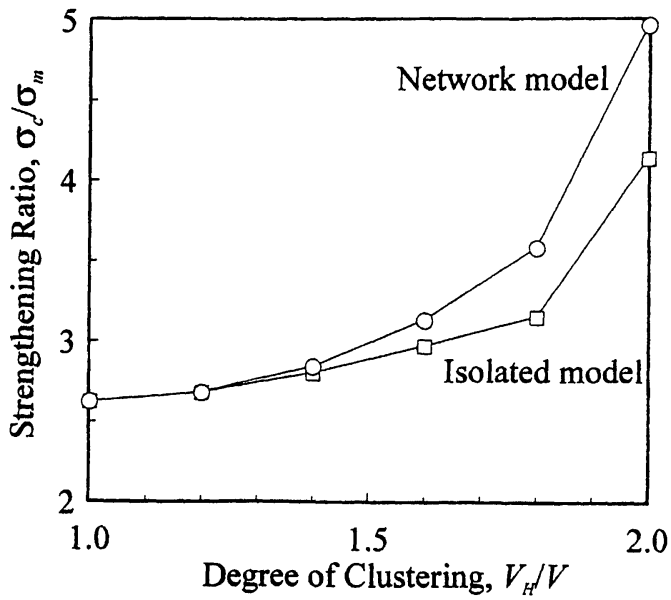

Fig. 22 Finite element predictions of strengthening ratio, $\sigma_{\mathrm{c}} / \sigma_{\mathrm{m}}$ as a function of degree of clustering in the networking and isolated models. The materials are $\mathrm{SiC}_{\mathrm{p}} / 99.99 \% \mathrm{Al}$. Total and local volume fractions are 11 and 25 , respectively. $\sigma_{\mathrm{c}}$ and $\sigma_{\mathrm{m}}$ are defined at $1 \% \varepsilon$. 


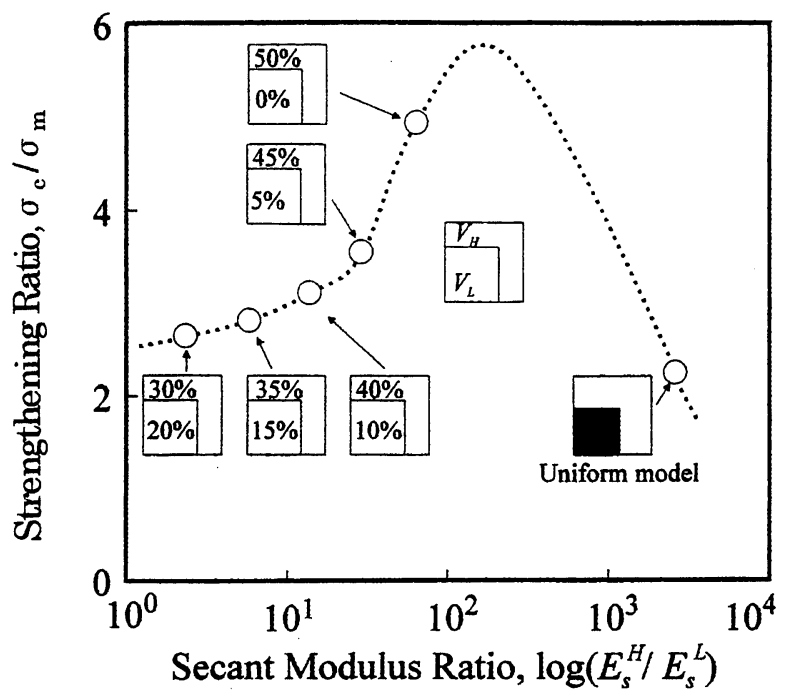

(a) $25 \% \mathrm{SiCp} / 99.99 \% \mathrm{Al}$

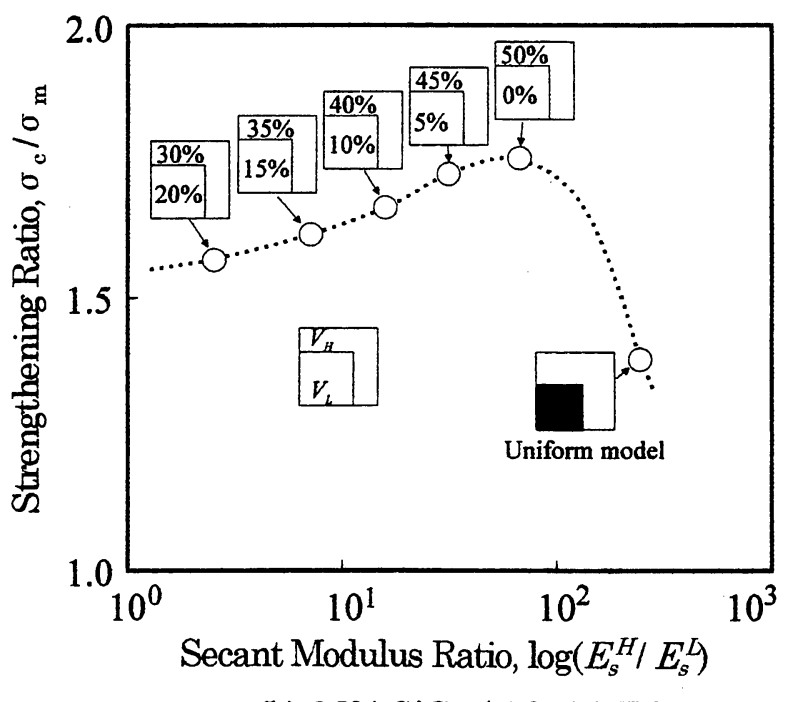

(b) $25 \% \mathrm{SiCp} / \mathrm{A} 2124-\mathrm{T} 6$

Fig. 23 The same prediction with Fig. 22. Degree of clustering is expressed by the secant modulus ratios, $E_{s}^{\mathrm{H}} / E_{s}^{\mathrm{L}} . \mathrm{H}$ and $\mathrm{L}$ mean cluster and low Vf region, respectively. $\sigma_{\mathrm{c}}$ and $\sigma_{\mathrm{m}}$ are defined at $0.4 \% \varepsilon$.

- a crack shorter than several millimeters grows rapidly and where it is easily affected by grain boundaries and other microstructures,

- the crack length is shorter than the plastic zone region at the tip of the crack, or

- the crack is affected by the strain field in the vicinity of a notch-tip.

Due in part to the fact that the crack closure mechanism is insufficient, these kinds of short fatigue cracks grow even below the threshold level, $\Delta K_{\mathrm{th}}$, of long cracks, and the growth speed is even faster. ${ }^{21)}$ Figure 26 shows the growth rates of short fatigue cracks of 6061 alloy and the composite material. The growth rate is high even below $\Delta K_{\text {th }}$ of long cracks and is lowest for the composite material at crack lengths of about 25 to $40 \mu \mathrm{m}$. Figure 27 shows the relationship between crack length and the shape parameter of the Weibull distribution that represents the distribution of crack growth rate. The shape parameter becomes almost constant at crack lengths of 110 to

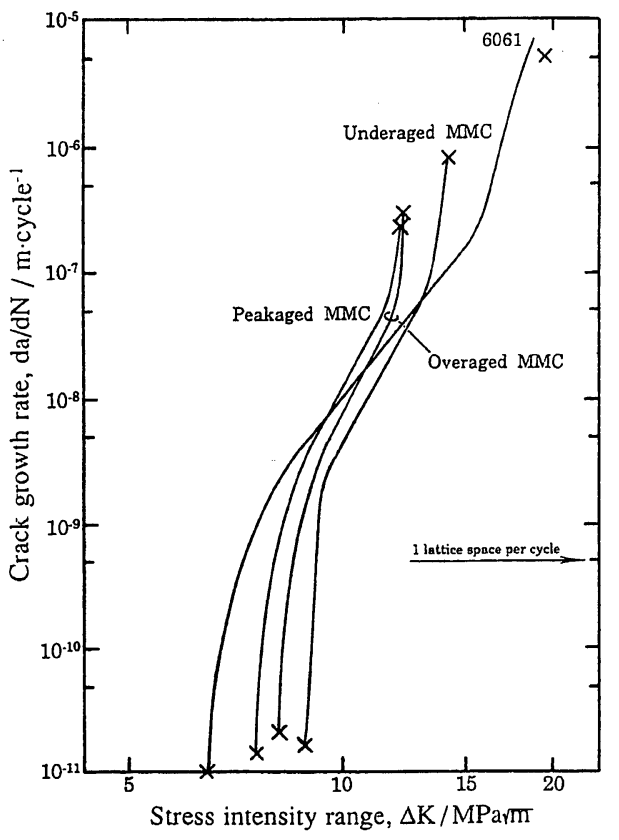

Fig. 24 Fatigue crack growth rate, $\mathrm{d} a / \mathrm{d} N$, as a function of stress intensity factor $\Delta K$ in $22 \% \mathrm{SiC}_{\mathrm{w}} / 6061 \mathrm{Al}$ composites.

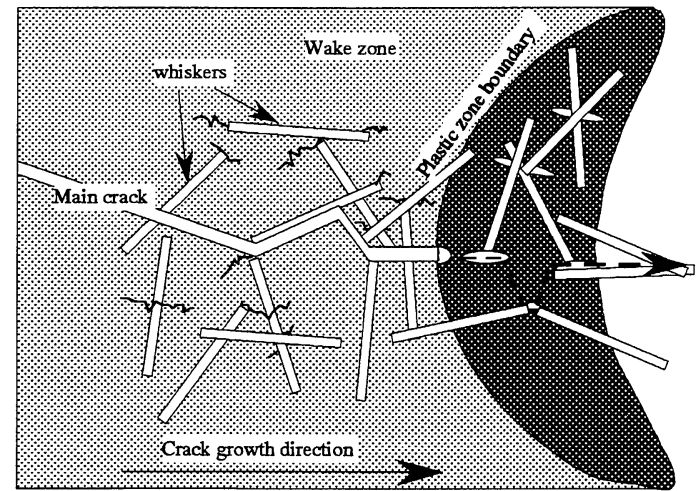

Fig. 25 Schematic representation of fatigue crack propagation mechanism in the whisker reinforced composite material at stage II b.

$183 \mu \mathrm{m}$ for the 6061 alloy and 25 to $40 \mu \mathrm{m}$ for the composite material. These values are considered to correspond to the upper limits of microstructurally short fatigue cracks where microscopic factors are no longer applicable. These values may also correspond to the grain size order in the case of the 6061 alloy and the inter-particle spacing of reinforcement in the case of the composite material. ${ }^{21)}$ The minimum values shown in Fig. 26 may also have some relations to this.

\section{Conclusion}

Based on the authors' past studies on various advanced and conventional materials, this paper introduced the experimental observation and mechanical analysis, from a micromechanics and continuum mechanics perspective, that was conducted in order to clarify the microscopic damage behavior, deformation and fracture behavior, and fatigue crack initiation and growth behavior. The characteristics of these behaviors should be understood, so that the deformation and fracture behaviors of various materials can be discussed in terms 


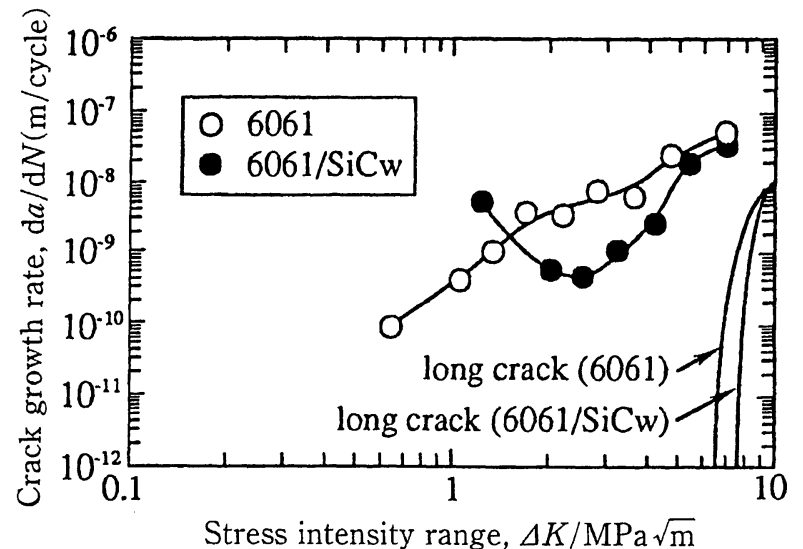

Fig. 26 Short fatigue crack growth rate curves as a function of the stress intensity range in $22 \% \mathrm{SiC}_{\mathrm{w}} / 6061 \mathrm{Al}$ composites.

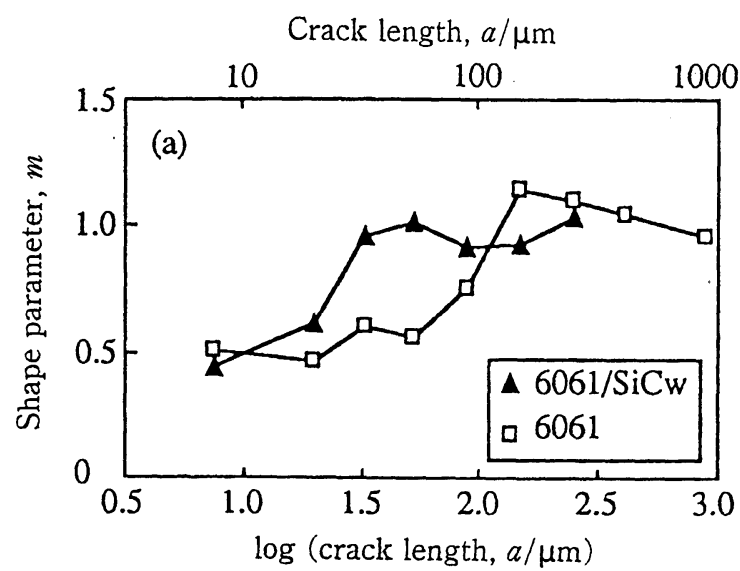

Fig. 27 Shape parameters in Weibull plots for propagation rate of short fatigue cracks through $22 \% \mathrm{SiC}_{\mathrm{w}} / 6061 \mathrm{Al}$ composite, representing scattering of the rates.

of their similarities and differences. Certain phenomena that already constitute common knowledge in the field of composite materials, should be strongly considered in the field of conventional materials. Examples of such phenomena are the thermal residual stress generated by a mismatch in the thermal expansion coefficient between the reinforcement and the matrix, the subsequent work hardening of the matrix by dislocation punching, the stress increase in hard phases that have a high Young's modulus and deforms only elastically, and the influences of orientation and dispersion. It is important to note that the microstructures and textures of the matrix of conventional materials differ to that of composite materials because of the addition of reinforcement. The description and prediction of the mechanical properties of materials is possible only after adequately investigating both advanced and conventional materials.

\section{REFERENCES}

1) T. Kobayashi and H. Yamamoto: Inter. J. of Mater. Product Tech. 14 (1999) 320-341.

2) S. Komatsu, T. Shiota and K. Nakamura: J. of Japan Foundry Engng. Soc. 60 (1988) 643-648.

3) T. Kobayashi and H. Yamamoto: Proc. Inter. Sympo. on Design, Process and Properties of Adv. Engng. Mater. ed. by T. Kobayashi et al. Toyohashi (1997) 373-378.

4) T. Kajino, K. Uwai, T. Kobayashi, Y. Hirakuchi and S. Adachi: Trans. JSME 55 (1989) 1173-1179.

5) T. Kobayashi, M. Niinomi, K. Uwai and S. Adachi: Heat \& Surface '92, 357-360.

6) H. Tanaka, T. Kobayashi, F. Nakazato and M. Uno: Tetsu-to-Hagane 79 (1993) 90-97.

7) T. Kobayashi, M. Niinomi and K. Degawa: Mater. Sci. Tech. 5 (1989) 1013-1019.

8) K. T. Venkateswara Rao, W. Yu and R. O. Ritchie: Met. Trans. 20A (1989) 485-497.

9) T. Kobayashi, M. Niinomi, I. Kanoya and H. Yamada: Proc. ICSMA-10, ed. by Oikawa et al. Sendai (1994) 447-450.

10) A. Takahashi, T. Kobayashi and H. Toda: Inter. J. of Mater. and Product Tech. 14 (1999) 217-228.

11) H. Toda, T. Kobayashi and A. Takahashi: Aluminum Transactions 1 (1999) 109-116.

12) H. Toda, N. Inoue and T. Kobayashi: Proc. Inter. Sympo. on Design, Process and Properties of Adv. Engng. Mater., ed. by T. Kobayashi et al. (Toyohashi, 1997) 577-582.

13) Y. Flom and R. J. Arsenault: Mat. Sci. Eng. 77 (1986) 191-197.

14) H. Toda and T. Kobayashi: Metall. Trans. A 28A (1997) 2149-2157.

15) T. Kobayashi and H. Toda: Mater. Sci. Forum 217-222 (1996) 11271132.

16) H. Toda, T. Kobayashi and N. Inoue: J. Japan Inst. Met. 61 (1997) 120127.

17) T. Kobayashi and H. Toda: Processing and Fabrication of Advanced Materials $V$, ed. by T. S. Srivatsan et al. TMS (1996) 255-264.

18) T. Kobayashi and H. Toda: Processing and Fabrication of Advanced Materials V, ed. by T. S. Srivatsan et al. TMS (1996) 69-78.

19) H. Toda, T. Goda and T. Kobayashi: Mater. Sci. Tech. 14 (1998) 925932.

20) H. Toda and T. Kobayashi: Proc. of 3rd. Int. Conf. on Alum. Alloys, Ed. by L. Amberg et al. (Norwegian Inst. Tech. Trondheim, 1992) 635-643.

21) H. Toda and T. Kobayashi: Metall. Mater. Trans. A 27A (1996) 20132021. 